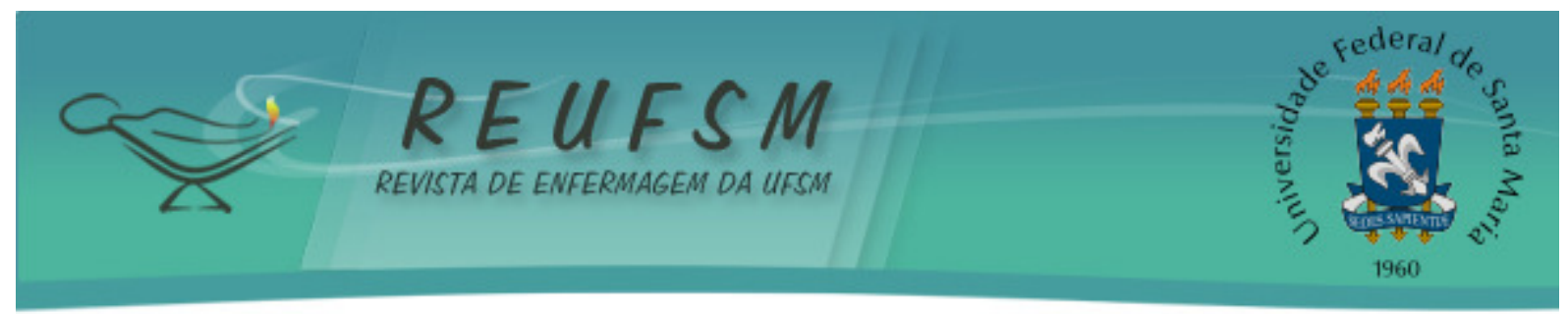

ARTIGO ORIGINAL

\title{
ACOLHIMENTO E HUMANIZAÇÃO DA ASSISTÊNCIA EM PRONTO-SOCORRO ADULTO: PERCEPÇÕES DE ENFERMEIROS
}

\section{HEALTHCARE RECEPTION AND HUMANIZED ASSISTANCE IN THE EMERGENCY ROOM FOR ADULTS: NURSES' PERCEPTIONS}

\section{RECEPCIÓN Y HUMANIZACIÓN DE LA ASISTENCIA EN EMERGENCIA PARA ADULTOS: PERCEPCIONES DE ENFERMEROS}

\author{
Alcides Viana de Lima Neto ${ }^{1}$ \\ Vilani Medeiros de Araújo Nunes ${ }^{2}$ \\ Rafaella Leite Fernandes ${ }^{3}$ \\ Ilcarla Mayara Lopes Barbosa ${ }^{4}$ \\ Gysella Rose Prado de Carvalho ${ }^{5}$
}

RESUMO: Objetivo: descrever as percepções dos enfermeiros que trabalham em um pronto-socorro de atendimento para pacientes adultos acerca da humanização e acolhimento com classificação de risco. Método: estudo descritivo, exploratório e qualitativo realizado por meio de um questionário estruturado e entrevista semiestruturada com 14 enfermeiros. A amostra foi composta por enfermeiros com predominância do sexo feminino (86\%), com idade média de 38 anos. 0 material das entrevistas foi analisado utilizando a técnica de Análise de Conteúdo. Resultados: a análise das entrevistas foi categorizada e agrupada por meio das características semelhantes, extraindo-se a temática da humanização, do acolhimento, classificação de risco e política nacional de humanização a partir das percepções dos entrevistados. Considerações Finais: os sujeitos entendem os conceitos ampliados de acolhimento e humanização, porém, a prática depende da forma como cada um os aplica, tornando essa atividade uma subjetividade que envolve o cotidiano profissional.

Descritores: Enfermagem em Emergência; Humanização da assistência; Acolhimento; Serviços médicos de emergência.

ABSTRACT: Aim: to describe the perceptions of nurses that work in the adults emergency room on humanized assistance and healthcare reception and risk classification. Method: it is a descriptive, exploratory and qualitative study carried out through a structured questionnaire and a semi-structured interview with 14 nurses. The sample was composed by nurses mainly women (86\%), the average age of 38 years old. The data collected through the interviews was analyzed using the content analysis technique. Results: the data collected was categorized and grouped by similar characteristics, extracting the theme of humanization, the healthcare reception, risk classification and National Policy of Humanization. Final Considerations: the interviewees understand the broader concepts of healthcare reception and humanization,

\footnotetext{
${ }^{1}$ Enfermeiro. Especializando em gestão em enfermagem pela Universidade Federal de São Paulo (UNIFESP). Enfermeiro assistencial da Casa de Saúde São Lucas, Natal, RN, Brasil. E-mail: alcides.vln@gmail.com

${ }^{2}$ Enfermeira. Doutora em Ciências da Saúde pelo Programa de Pós-Graduação em Ciências da Saúde da Universidade Federal do Rio Grande do Norte (UFRN). Professora Adjunta do Departamento de Saúde Coletiva (DSC) da UFRN. Natal, RN, Brasil. E-mail: vilani.nunes@gmail.com

${ }^{3}$ Enfermeira. Mestre em Enfermagem pelo Programa de Pós-Graduação em Enfermagem da UFRN. Natal, RN, Brasil. E-mail: perrequel@yahoo.com.br

${ }^{4}$ Enfermeira graduada pela Faculdade Estácio do Rio Grande do Norte (Estácio/FATERN). Natal, RN, Brasil. Email: ilcarla_mayara@hotmail.com

${ }^{5}$ Enfermeira. Mestre em Enfermagem pelo Programa de Pós-Graduação em Enfermagem da UFRN. Professora da Faculdade de Sergipe (FASE). Natal, RN, Brasil. E-mail: gysella.carvalho@yahoo.com.br
} 


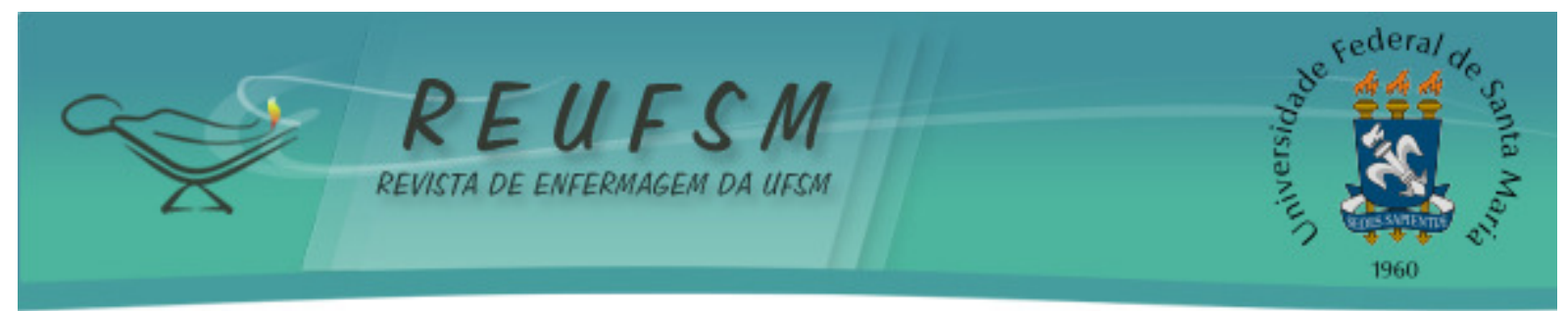

however, the practice depends on the way each professional applies them, transforming this activity into a subjectivity that involves daily work.

Descriptors: Emergency Nursing; Humanization of assistance; User embracement; Emergency medical services.

RESUMEN: Objetivo: describir las percepciones de los enfermeros que trabajan en un servicio de urgencias para adultos sobre la humanización y la acogida con calificación de riesgo. Método: estudio descriptivo, exploratorio y cualitativo a través de un cuestionario estructurado y entrevistas semiestructuradas con 14 enfermeros. La muestra fue composta por enfermeros con predominio del sexo femenino (86\%) con edad media de 38 años. El material de las entrevistas se analizó mediante la técnica de análisis de contenido. Resultados: El análisis de las entrevistas fue clasificado y agrupado por características similares, extrayendo el tema de la humanización, la recepción, clasificación de riesgo y política nacional de humanización a partir de las percepciones de los entrevistados. Consideraciones finales: los sujetos entrevistados entienden los conceptos expandidos de recepción y humanización, sin embargo, la práctica depende de cómo se aplica, haciendo de esta actividad una subjetividad que implica en el trabajo diario.

Descriptores: Enfermería de Urgencia; Humanización de la atención; Acogimiento; Servicios médicos de urgência.

\section{INTRODUÇÃO}

O pronto-socorro (PS) é uma unidade destinada à assistência a pacientes com ou sem risco de morte, cujos agravos à saúde inspiram a necessidade de atendimento imediato. Sua estrutura deve estar adequada para prestar assistência em situações de urgência (casos que necessitam de atendimento rápido, porém sem risco de morte imediato) e emergência (risco iminente de morte). ${ }^{1}$

Embora as Políticas Públicas estabelecidas pelo Ministério da Saúde fortaleçam a Atenção Básica à comunidade como forma de promoção à saúde e prevenção de agravos, a falta de estrutura dos serviços dos municípios enfraquece a assistência tornando os PS as "portas de entrada" do sistema de saúde. Ressalta-se que, a Portaria $n^{\circ} 1.600$, de 7 de julho de 2011 reformulou a Política Nacional de Atenção às Urgências e instituiu a Rede de Atenção às Urgências no Sistema Único de Saúde (SUS) ${ }^{2}$.

Nesse sentido, surge a discussão sobre humanização que procura traduzir de maneira prática o sentido de revisão paradigmática das práticas de saúde, em que as necessidades integrais do paciente passam a ser o foco, ao invés da abordagem centrada na doença. ${ }^{3}$

A humanização da assistência é entendida como um conjunto de diretrizes e princípios que afirmam a valorização dos diferentes sujeitos implicados no processo de produção de saúde (usuários, trabalhadores e gestores); o fomento da autonomia e do protagonismo desses sujeitos; o aumento do grau de corresponsabilidades; o estabelecimento de vínculos solidários e de participação coletiva no processo de gestão; a identificação das necessidades sociais de saúde, dos usuários e dos trabalhadores; e o compromisso com a ambiência, com a melhoria das condições de trabalho e de atendimento. ${ }^{4}$

Em 2003 foi instituída no Brasil a Política Nacional de Humanização (PNH) que traduz princípios e modos de operar no conjunto das relações entre todos que constituem o SUS, incluindo os diferentes níveis de complexidade de atendimento. ${ }^{5}$

Nos serviços de PS, o acolhimento com classificação de risco (ACR) é colocado como uma das diretrizes específicas da PNH. É caracterizado por acolher a demanda por meio de critérios de avaliação de risco, garantindo o acesso referenciado aos demais níveis de assistência. ${ }^{6}$ 


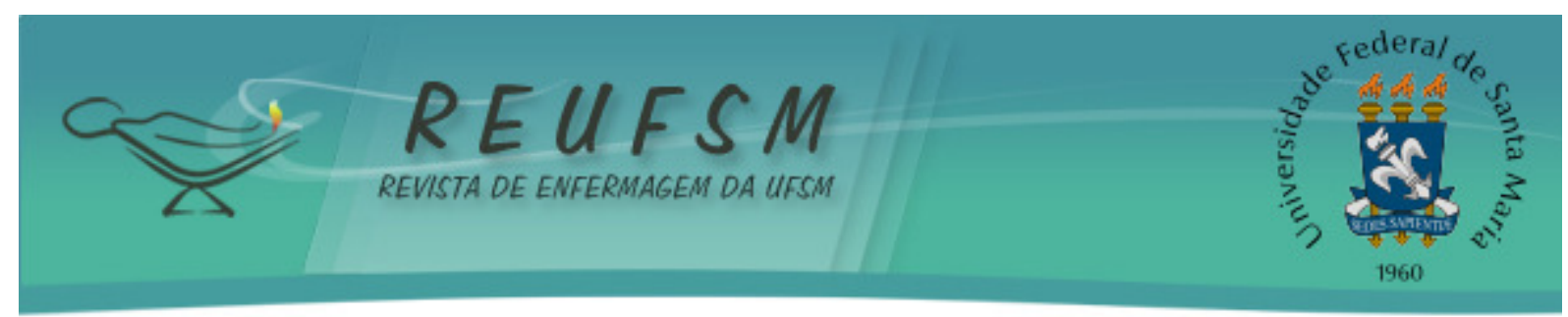

Quando o paciente é acolhido e encaminhado para atendimento por ordem de chegada, sem o estabelecimento de critérios clínicos, a situação de superlotação dos serviços pode ser agravada, bem como a sua situação atual de saúde-doença. Para tanto, tem sido utilizado o acolhimento com classificação de risco que consiste em um processo dinâmico de identificação de pacientes que necessitam de tratamento imediato, de acordo com a gravidade clínica do seu caso. ${ }^{7}$

O enfermeiro é o profissional indicado para classificar os pacientes de acordo com o seu estado clínico nos serviços de urgência e emergência após treinamento específico para tal função. Ele deve orientar-se por protocolos padronizados pela instituição. ${ }^{8}$

0 profissional deve escutar a queixa, os medos e as expectativas, identificar os riscos e vulnerabilidades. Deve acolher também a avaliação do próprio usuário e se responsabilizar para dar uma resposta adequada ao problema, conjugando as necessidades imediatas dos usuários com as ofertas do serviço. Portanto, o sucesso no atendimento oferecido depende tanto da qualidade técnica com que ele é realizado quanto da qualidade das interações entre os sujeitos que o fazem, no caso o profissional e o usuário. ${ }^{8-9}$

A necessidade de estudos na área de acolhimento e humanização de um Pronto-Socorro Adulto (PSA) foi decorrente de experiências vivenciadas durante a realização de estágio em um hospital situado no município do Natal, Rio Grande do Norte, sob a gestão da Secretaria Estadual de Saúde do Rio Grande do Norte (SESAP - RN). Nesse contexto, surge o questionamento que instiga e motiva a investigação deste trabalho: Quais as percepções dos enfermeiros que trabalham no PSA acerca da humanização e acolhimento com classificação de risco?

Dessa forma, o objeto de pesquisa constitui-se das percepções dos enfermeiros que atuam no serviço escolhido no que diz respeito às questões da problemática da pesquisa, ou seja, é representado pelo estudo da humanização e do acolhimento entendido pelo grupo de profissionais pesquisado.

Portanto, este estudo tem como objetivo geral descrever as percepções dos enfermeiros que trabalham no pronto-socorro para pacientes adultos acerca da humanização e acolhimento com classificação de risco no setor.

\section{MÉTODO}

Trata-se de uma pesquisa descritiva e exploratória com abordagem qualitativa, realizada por meio da coleta de informações dos enfermeiros que atuam no PSA de um hospital geral, público e estadual situado em Natal, RN, Brasil. Esse hospital foi escolhido por ser uma importante instituição de saúde com referência para atendimento de urgência e emergência na Zona Norte do município de Natal e cidades da região metropolitana, além de ser o local onde foi vivenciada a experiência que motivou o desenvolvimento desta pesquisa.

Como critérios de inclusão para sujeitos participantes da pesquisa foram adotados os seguintes: enfermeiros que trabalhavam predominantemente no PSA há mais de seis meses; e estavam, no período da pesquisa, na escala de trabalho do PSA. Foram excluídos da pesquisa os enfermeiros que não atuavam predominantemente no PSA; enfermeiros que trabalhavam no PSA, porém, no período da pesquisa não estavam na escala de trabalho do referido setor e enfermeiros que se encontravam de férias ou afastados do trabalho por quaisquer outros motivos.

Tendo em vista que o hospital apresentava 58 enfermeiros em seu quadro profissional, somente 18 estavam escalados para o PSA no período da pesquisa, que se deu nos meses de julho, agosto e setembro de 2011. Dos 18 enfermeiros, 14 enquadraram-se nos critérios de inclusão adotados e aceitaram participar do estudo constituindo o corpus amostral.

Foi utilizado como instrumento de coleta de dados um questionário estruturado com perguntas abertas e fechadas para caracterização dos participantes do estudo. Nesse questionário, solicitou-se que o enfermeiro escolhesse um codinome em uma lista 


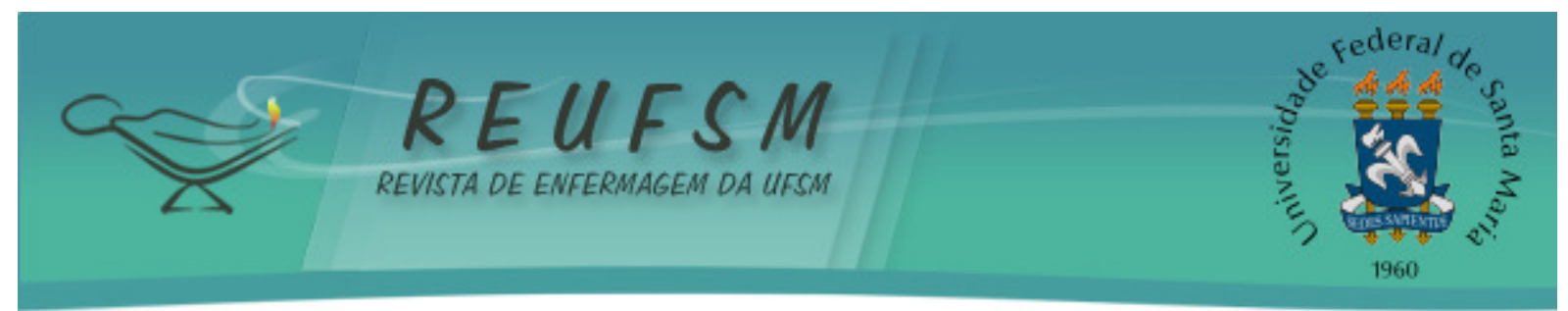

disponível para que fosse mantido o sigilo na identificação. A lista dos codinomes foi composta de materiais e equipamentos utilizados nos serviços de urgência e emergência. Após o preenchimento do questionário, foi realizada uma entrevista semiestruturada conduzida por um roteiro pré-estabelecido.

O conteúdo das entrevistas foi analisado por meio da técnica de Análise de Conteúdo, que consiste em:

[...] um conjunto de técnicas de análise das comunicações visando obter, através de procedimentos sistemáticos e objetivos a descrição do conteúdo das mensagens, indicadores (quantitativos ou não) que permitam a inferência de conhecimentos relativos às condições de produção/recepção (variáveis inferidas) dessas mensagens. ${ }^{10: 37}$

Os textos das entrevistas, após a leitura flutuante, foram agrupados por características semelhantes de acordo com os temas extraídos das falas e a seguir, confrontados com a literatura disponível.

A pesquisa foi aprovada pelo Comitê de Ética em Pesquisa da Universidade Federal do Rio Grande do Norte (CEP - UFRN) pelo parecer número 267/2011. Todos os participantes leram e assinaram Termo de Consentimento Livre e Esclarecido (TCLE). Todo o processo de construção levou em consideração os preceitos da Resolução n 196/96 do Conselho Nacional de Saúde (CNS) que é responsável por aprovar as diretrizes e normas regulamentadoras de pesquisas envolvendo seres humanos. ${ }^{11}$

\section{RESULTADOS E DISCUSSÃO}

\section{Caracterização sócio-demográfica dos participantes do estudo e formação profissional}

Quanto ao sexo, observou-se predominância de mulheres (86\%). 0 grupo estudado apresentou característica jovem, com uma idade média de 38 anos. No que se refere ao estado civil, a maioria dos participantes (43\%) eram solteiros e $64 \%$ afirmaram possuir apenas um vinculo empregatício.

A formação profissional superior deu-se, na maioria $(71,42 \%)$, há mais de quatro anos e 50\% da amostra possui Pós-Graduação Latu Sensu (Especialização). No questionamento a respeito da experiência profissional em urgência e emergência, o maior percentual ficou com a categoria entre dois a quatro anos $(42,86 \%)$. Uma quantidade considerável dos entrevistados foi admitida no hospital a partir de um concurso público realizado no ano de 2008 e outro no ano de 2010, sendo o PSA o primeiro setor para o qual foram alocados, continuando até o período da pesquisa. Provavelmente, seja essa, a justificativa para o tempo de experiência profissional em urgência e emergência, apresentar frequência relativa significativa na faixa de 2 a 4 anos, com 42,86\%.

\section{Humanização sob a ótica dos participantes: reflexões sobre a prática}

Com o objetivo de tornar os princípios do SUS mais operativos na prática, a PNH enfatiza que a humanização é um instrumento para a mudança nos modelos de atenção e gestão, tendo como foco as necessidades dos cidadãos, a produção de saúde e o próprio processo de trabalho em saúde, valorizando os profissionais e as relações sociais que envolvem o contexto do trabalho. ${ }^{12}$

Nesse sentido, conforme reproduzido nas falas a seguir, a humanização é entendida de diferentes formas, porém com conversão para um mesmo significado, o da valorização do ser humano. 


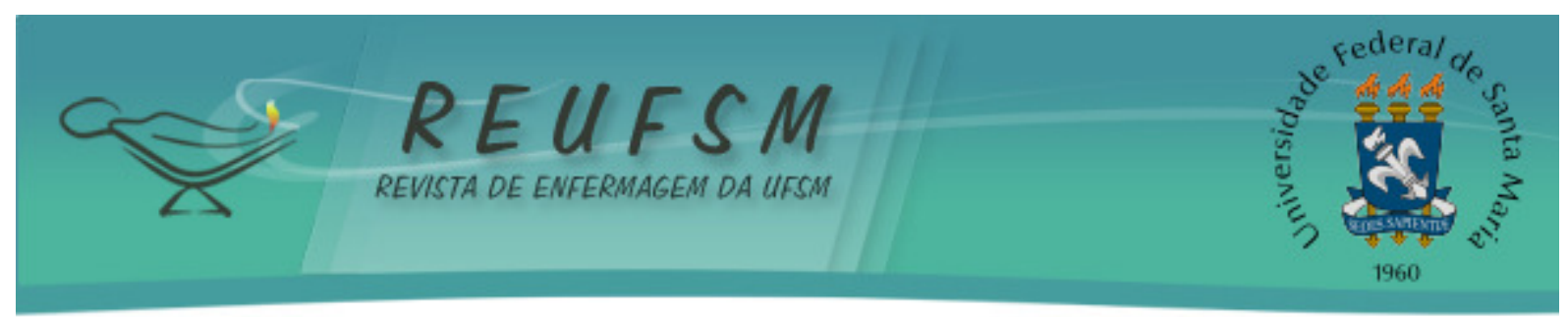

É fazer valer alguns direitos [...] e permitir que ele seja atendido de uma forma digna e você também fornecer a melhor assistência possível. (Desfibrilador)

[...] respeitar as condições do outro, prestar atendimento com ética, escutar o paciente, dar orientações quando ele pede, acolher ele bem [...]. (Oxímetro de pulso)

No geral, são abordados os aspectos relacionados ao ser humano em publicações que tratam do conceito de humanização. Tais aspectos direcionam para percebê-lo como um ser único e insubstituível, por meio da inclusão de parâmetros sociais, éticos, educacionais e psíquicos. ${ }^{13}$

Foi relatada a questão dos direitos que o indivíduo possui perante as políticas públicas e legislação vigente. Ante esses direitos, é interessante destacar a Declaração Universal dos Direitos Humanos (DUDH), proclamada pela Assembléia Geral das Nações Unidas em Paris, em 10 de dezembro de 1948. Esta, afirma que todos os cidadãos nascem livres e iguais em dignidade e direitos, tendo, dessa forma, o direito de acesso aos serviços públicos de seu país. ${ }^{14}$

Essa temática está relacionada com o código de ética dos profissionais de enfermagem que veicula o respeito à vida, a dignidade e os direitos humanos, em todas as suas dimensões. Além disso, as atividades devem ser exercidas com competência para a promoção da integralidade em todas as ações para com o ser humano, de acordo com os princípios da ética e da bioética. ${ }^{15}$ Tais ideias fazem parte do contexto da humanização enfatizado pelos profissionais entrevistados, conforme foi reproduzido nos trechos citados anteriormente.

A escuta, colocada como ponto importante, faz parte do processo de comunicação. 0 enfermeiro deve estar disposto a conversar e dialogar, ouvir o paciente e permitir que ele apresente as suas necessidades de saúde e/ou doença. ${ }^{16}$

A construção da humanização se dá também quando ocorre interação com base no diálogo entre o profissional e o cliente. A humanização depende da capacidade de falar e de ouvir. Por meio da comunicação, as identidades subjetivas são acessadas e colaboram para uma assistência de qualidade e para a valorização do paciente em sua dignidade. ${ }^{17}$

Ao falar em humanização, alguns trechos remetem para a questão da desumanização:

O próprio trabalhador não é humanizado pelas próprias condições de trabalho que eles são expostos, que eles são colocados [...]. (Laringoscópio)

\section{Eu acho esse pronto-socorro tão desumano. (Termômetro)}

A palavra desumanização apresenta um forte impacto. Ao ser analisada mais profundamente aponta para o fato de perca dos atributos humanos ou ainda, perca da dignidade, interagindo com o termo despersonalização. ${ }^{18}$

Desde a década de 50 , século $X X$, estudos apontam vários aspectos considerados desumanizantes, dentre eles as falhas no atendimento e nas condições de trabalho. Para eles, cada indivíduo possui sua singularidade constituída a partir de uma identidade única. 0 profissional deve ser sensível a esse fato e não conduzir a um tratamento rotinizado, padronizado e impessoal. ${ }^{17}$

A sensibilidade é apresentada em pontos da análise do conteúdo das entrevistas: 


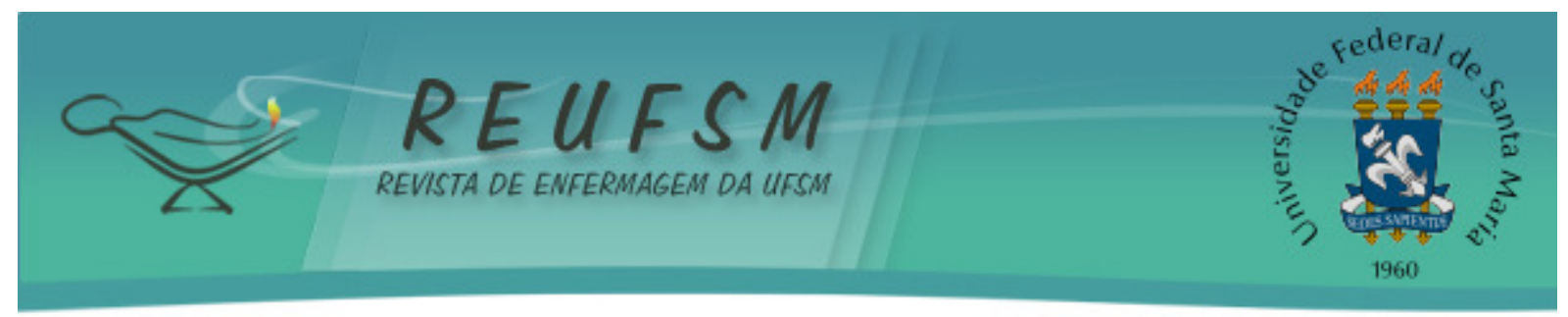

[...] a gente por outro lado vai estar perdendo a sensibilidade ou qualquer filosofia que alimenta este desejo de estar tentando procurar trabalhar de uma forma humanizada [...]. (Laringoscópio)

[...] não adianta eu ser bem recebido, eu ser levado e mostrado onde é que eu tenho que ir, se quem vai me receber nos outros setores não está sensibilizado para isso, que é o que acontece no pronto-socorro [...]. (Ampola)

Percebe-se então que os participantes entendem o processo de humanização, porém, as condições e os fatores aos quais envolvem o contexto de trabalho muitas vezes não proporcionam um atendimento com qualidade e humanizado, conforme preconiza a $\mathrm{PNH}$.

\section{Percepções sobre o acolhimento}

No que diz respeito ao acolhimento, o conhecimento tem sido, muitas vezes, limitado à forma ou a uma atitude profissional de bondade e favor, bem como a uma recepção com ambiente confortável. No entanto, em composição mais ampliada, pode ser caracterizado como a adoção de uma postura de aproximação e responsabilização durante o desenvolvimento das ações de atenção e gestão, favorecendo a confiança e o compromisso entre usuários, equipes e serviços. ${ }^{19}$ de acolhimento:

Os enfermeiros entrevistados fizeram as seguintes citações a respeito do processo

É você estar atento, esclarecendo, tirar as dúvidas, recepcioná-lo bem, [...] Tentar dar uma continuidade da assistência, mas que seja resolvida a necessidade a qual ele procurou atendimento aqui no hospital. (Desfibrilador)

Receber bem e ter as condições. Não é só receber bem, porque eu posso receber bem, mas o hospital não. Então é um conjunto [...]. (Maca)

O acolhimento é mais que uma atividade de recepção no serviço encarregado a um determinado profissional ou em um local específico. Trata-se de uma técnica de conversa que pode ocorrer em qualquer momento do atendimento e que ajuda no conhecimento das necessidades que os usuários buscaram por atendimento. ${ }^{20}$

Para alguns autores, o acolhimento é entendido como um espaço que visa a escuta, a identificação das necessidades a partir dos relatos sobre as queixas e o respeito às diferenças, devendo ser baseadas no diálogo e construídas relações humanizadas entre quem cuida e quem é cuidado, afastando-se um pouco do foco da doença e valorizando-se os aspectos sociais, econômicos, crenças, valores e histórias de vida. ${ }^{21}$

Alguns participantes afirmaram que existe acolhimento, conforme relatos abaixo:

[...] existe acolhimento de forma humanizada por parte de alguns profissionais. (Oxímetro de Pulso)

[...] a gente tem um acolhimento [...]. (Bomba de Infusão Contínua - BIC)

Percebe-se que no geral, os profissionais detém o conceito ampliado de acolhimento e entendem que para que seja colocado em prática, vários fatores são 


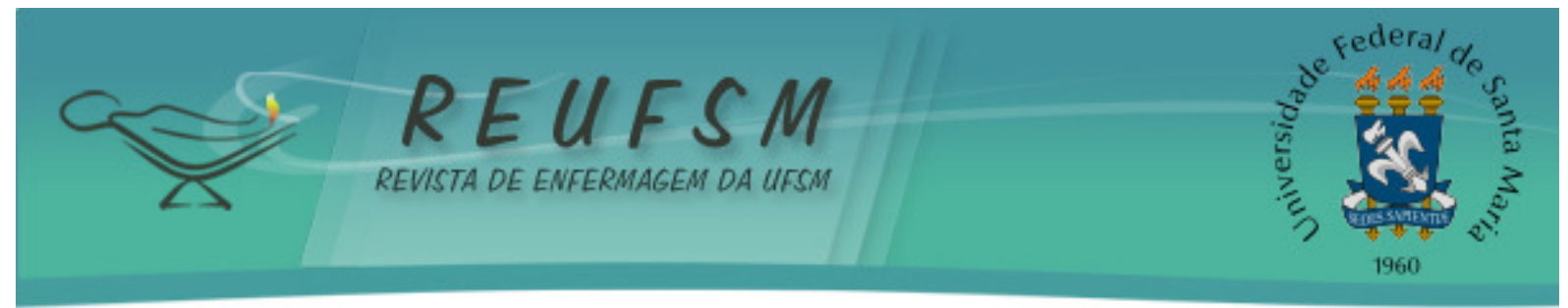

determinantes. Apesar de depender de vários fatores, algumas pessoas ainda tentam e conseguem prestar uma assistência de forma humanizada e acolhedora.

\section{A Política Nacional de Humanização}

Um ponto importante a ser comentado é a PNH. Esta firma um compromisso e coloca a saúde não como valor de troca, mas como valor de uso com ênfase no vínculo com os usuários. Por meio dela, ocorre o estímulo ao controle social e garantia de melhores condições para os trabalhadores e gestores realizarem seu trabalho. ${ }^{22}$

Os participantes da pesquisa mostraram pouco conhecimento em relação à $\mathrm{PNH}$, como é relatado a seguir:

Eu já ouvi falar. Já li na época de faculdade e ainda me lembro um pouco. (Desfibrilador)

Eu já ouvi falar. Agora se você me perguntar sobre o que ela traz, eu não vou saber lhe dizer agora, mas eu já cheguei a ler também, de forma rápida. (Agulha)

Nenhum dos sujeitos mostrou segurança em falar da PNH, bem como o conhecimento completo a respeito da política, ao serem questionados se conheciam a mesma. Esperava-se que, servidores de uma unidade de urgência e emergência conhecessem os aspectos relevantes da política, tendo em vista que a mesma deveria ser utilizada como instrumento de trabalho. Durante as entrevistas, foi notória a insegurança que os mesmos apresentavam ao serem questionados sobre a mesma.

A PNH aparece no cenário da assistência, como um projeto norteador de proposições e ações voltadas para a humanização dessa assistência, a partir de um diagnóstico que apontava para problemas que geravam e ainda geram insatisfações, não só por parte dos usuários, mas também de profissionais e gestores. ${ }^{23}$

Dentre os vários instrumentos colocados pela PNH para a melhoria da assistência, os enfermeiros participantes afirmaram que na instituição existem os seguintes:

Instituíram uma classificação de risco, que o nome não é classificação de risco. O nome é acolhimento com classificação de risco, esse seria o nome correto. Mas a famosa classificação, que o acolhimento está meio distante. (Maca)

[...] nós temos a questão da ambiência, [...] esse setor aqui que tem a televisão que é para os pacientes virem assistir[...], foi implantado a classificação de risco [...]. (Ampola)

O dispositivo predominante nas citações foi à classificação de risco. Apesar da falta de conhecimento sobre a PNH, grande parte sabe que a classificação de risco é um dos instrumentos utilizados por essa política para a prática do acolhimento e da humanização.

O acolhimento juntamente com a classificação de risco objetivam receber todos os usuários que procuram a instituição através de uma escuta qualificada, responsável e resolutiva. ${ }^{12}$

A prática do acolhimento com classificação de risco faz parte da rotina institucional, como é reproduzido nas falas a seguir: 


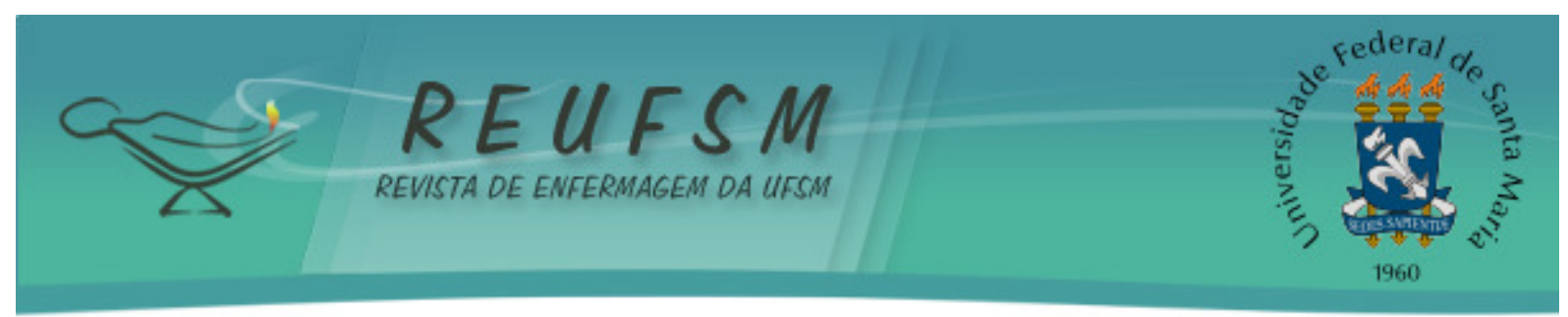

[...] quando o paciente chega vai ao setor do [serviço de arquivos médicos] (SAME) que é onde preenche a ficha, depois volta para a classificação onde são verificados os sinais, ele conta sua breve história ao profissional que está na classificação e logo em seguida é classificado. (Desfibrilador)

Ele é recebido primeiro na classificação, da classificação ele vai para o atendimento com o médico. Se for urgência é atendido primeiro, se não for vai ter que ficar lá numa fila esperando [...]. (Esparadrapo)

Estudo realizado em Pernambuco, identificou que em alguns hospitais a prática ainda ocorre centrada em casos de menor gravidade, com a carência de normas de atendimento específicas ao setor e com rotina de triagem elementar. Esse quadro descaracteriza a assistência aos casos de emergência, conduzindo a superlotação das unidades. Portanto, faz-se necessário o fortalecimento da estratégia de classificação de risco dos usuários por grau de risco de morte. ${ }^{24}$

A partir da interpretação de algumas falas, entende-se que são necessárias ações por parte dos gestores para a melhoria das condições e da prática da PNH na instituição conforme foi citado por alguns dos entrevistados:

[...] falta colocar em prática mesmo a política. Se essa política que está no papel fosse posta em prática iria melhorar bastante. (Maca)

Eu não vejo assim, a entidade fazer um trabalho voltado para isso não. Até diz assim ah, eu trabalho isso, mas não vejo esse trabalho, uma sensibilização realmente formal [...]. Cada um faz o trabalho humanizado que entende ser humanizado. (Ambulância)

A partir da análise global dos resultados, identificou-se que os participantes do estudo entendem os conceitos ampliados de humanização e de acolhimento, porém são frágeis no que diz respeito ao conhecimento e a aplicação da PNH como instrumento de trabalho no serviço ao qual desempenham suas atividades.

\section{CONSIDERAÇÕES FINAIS}

A realização da pesquisa revelou que os profissionais entendem os conceitos ampliados de humanização e acolhimento, percebendo a primeira não apenas como tratar o indivíduo que procura por atendimento bem, e sim um conjunto de vários aspectos. No que se refere ao processo de acolhimento, é perceptível que o grupo de profissionais estudado afirma que ele não está limitado apenas a receber bem, ma sim dar a garantia de uma assistência completa, resolutiva e com continuidade. A prática dos mesmos depende da forma como cada um os aplica, tornando essa atividade uma subjetividade que envolve o cotidiano profissional.

A partir da elaboração do referencial teórico para o desenvolvimento deste estudo pôdese verificar que a PNH, criada e difundida pelo Ministério da Saúde, reafirma que os serviços devem receber aos usuários de forma humanizada e acolhedora. Entretanto, ainda existe dificuldade na implementação de tal política, pois, muitos serviços não oferecem condições para a realização da mesma e exigem também a necessidade de capacitação dos profissionais.

O enfermeiro, considerado um importante profissional de saúde e, portanto um potencial utilizador e implementador da prática do acolhimento de forma humanizada 


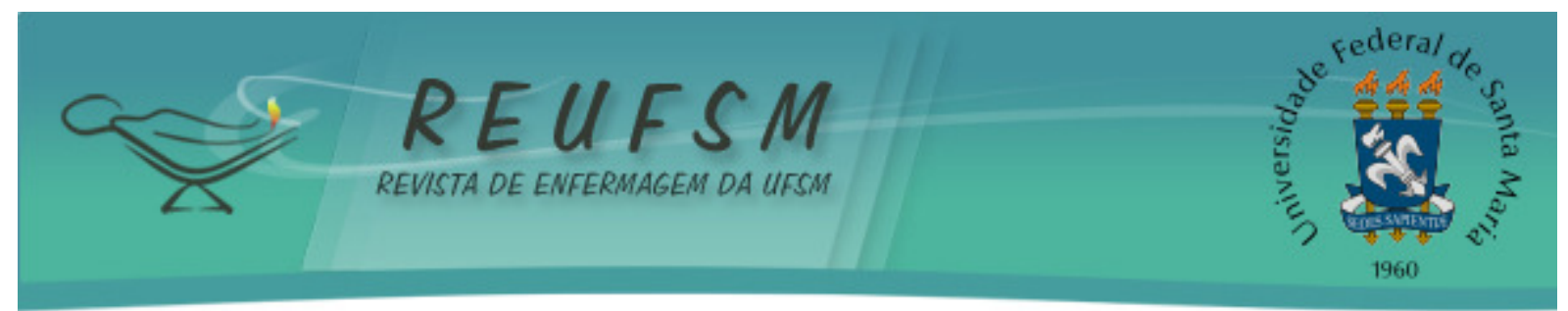

deve possuir competências e habilidades para o trabalho em um setor de urgência e emergência. Tal serviço demanda capacitação específica e a necessidade do profissional possuir raciocínio crítico e reflexivo e ser capaz de tomar decisões imediatas.

Destarte, o estudo apresenta importância para a prática por evidenciar percepções de servidores sobre os processos de humanização e de acolhimento no contexto do trabalho em urgência e emergência. A partir dos achados deste estudo, as práticas institucionais e profissionais poderão ser aperfeiçoadas para que uma melhor atenção seja oferecida aos usuários do serviço. Estudos mais aprofundados sobre as condições, fatores que facilitam e que dificultam tais práticas poderão ser desenvolvidos utilizando como subsídio os resultados aqui apresentados.

\section{REFERÊNCIAS}

1. Ohara R, Melo MRAC, Laus AM. Caracterização do perfil assistencial dos pacientes adultos de um pronto socorro. Rev Bras Enferm [Internet]. 2010 out [acesso em $2011 \mathrm{abr}$ 17];63(5):749-54. Disponível em: http://www.scielo.br/pdf/reben/v63n5/09.pdf.

2. Ministério da Saúde (BR). Portaria $N^{\circ} 1.600$, de 7 de julho de 2011. Reformula a Política Nacional de Atenção às Urgências e institui a Rede de Atenção às Urgências no Sistema Único de Saúde (SUS). Brasília (DF): Ministério da Saúde; 2011.

3. Bergan C, Bursztyn I, Santos COM, Tura LFR. Humanização: representações sociais do hospital pediátrico. Rev Gaúch Enferm [Internet]. 2009 dez [acesso em 2011 abr 17]; 30(4):656-61. Disponível em:

http://seer.ufrgs.br/index.php/RevistaGauchadeEnfermagem/article/view/13146/7540.

4. Deslandes SF, Mitre RMA. Processo comunicativo e humanização em saúde. Interface Comun Saúde Educ [Internet]. 2009 [acesso em 2011 maio 12];13 Supl 1:641-9. Disponível em: http://www.scielo.br/pdf/icse/v13s1/a15v13s1.pdf.

5. Falk MLR, Ramos MZ, Salgueiro JB. A rede como estratégia metodológica da Política Nacional de Humanização: a experiência de um hospital universitário. Interface Comun Saúde Educ [Internet]. 2009 [acesso em 2011 maio 15];13 Supl 1:709-17. Disponível em:a http://www.scielo.br/pdf/icse/v13s1/a22v13s1.pdf.

6. Ministério da Saúde (BR). Secretaria Executiva. Núcleo Técnico da Política Nacional de Humanização. HumanizaSUS: Política Nacional de Humanização: a humanização como eixo norteador das práticas de atenção e gestão em todas as instâncias do SUS. Brasília (DF): Ministério da Saúde; 2004.

7. Ministério da Saúde (BR). Secretaria Executiva. Núcleo Técnico da Política Nacional de Humanização. HumanizaSUS: acolhimento com avaliação e classificação de risco: um paradigma ético-estético no fazer em saúde. Brasília (DF): Ministério da Saúde; 2004.

8. Souza CC, Toledo AD, Tadeu LFR, Chianca TCM. Classificação de risco em prontosocorro: concordância entre um protocolo institucional brasileiro e Manchester. Rev Latinoam Enferm [Internet]. 2011 fev [acesso em 2011 jun 7];19(1):26-33. Disponível em: http://www.scielo.br/pdf/rlae/v19n1/05.pdf.

9. Lazzari DD, Jacobs LG, Jung W. Humanização da assistência na enfermagem a partir da formação acadêmica. Rev Enferm UFSM [Internet]. 2012 jan-abr [acesso em 2013 mar 13];2(1):116-24. Disponível em: http://cascavel.ufsm.br/revistas/ojs-

2.2.2/index. php/reufsm/article/view/3705/3133. 


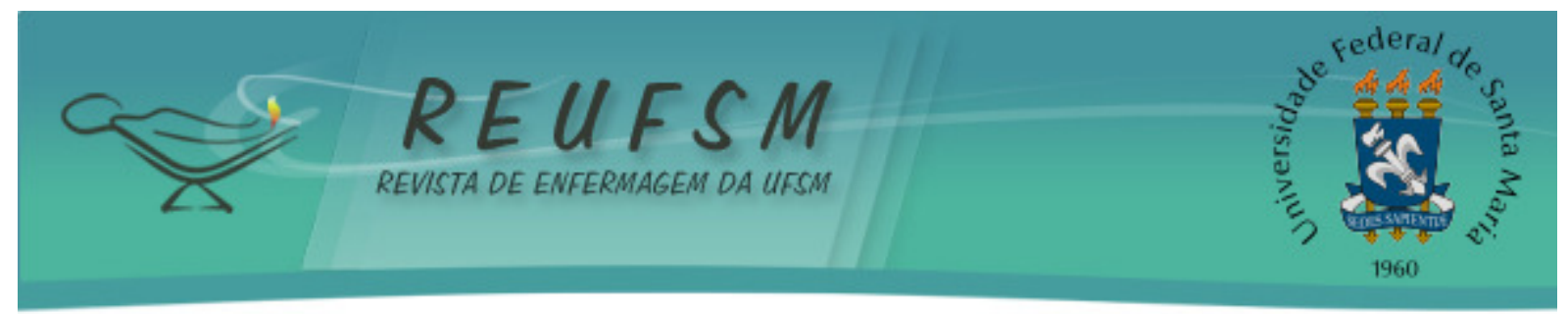

10. Bardin L. Análise de conteúdo. 3a ed. Lisboa: Edições 70; 2004.

11. Ministério da Saúde (Brasil). Conselho Nacional de Saúde. Resolução $n^{a}$ 196, de 10 de outubro de 1996. Aprova as diretrizes e normas regulamentadoras de pesquisa envolvendo seres humanos. Brasília (DF); 1996. [acesso em 2011 jun 7]. Disponível em: http: //bvsms.saude.gov.br/bvs/saudelegis/cns/1996/res0196_10_10_1996.html.

12. Andrade MAC, Artmann E, Trindade ZA. Humanização da saúde em um serviço de emergência de um hospital público: comparação sobre representações sociais dos profissionais antes e após a capacitação. Cienc Saúde Coletiva [Internet]. 2011 [acesso em 2011 out 1];16 Supl 1:1115-24. Disponível em: http://www.scielo.br/pdf/csc/v16s1/a43v16s1.pdf.

13. Casate JC, Corrêa AK. A humanização do cuidado na formação dos profissionais de saúde nos cursos de graduação. Rev Esc Enferm USP [Internet]. 2012 [acesso em 2013 jun 26];46(1):219-26. Disponível em: http://www.scielo.br/pdf/reeusp/v46n1/v46n1a29.pdf.

14. Organização das Nações Unidas. Declaração Universal dos Direitos Humanos [Internet]. UNIC/Rio; 2000 [acesso em 2011 jun 12]. Disponível em: http://unicrio.org.br/img/DeclU_D_HumanosVersolnternet.pdf.

15. Conselho Federal de Enfermagem. Código de Ética dos Profissionais de Enfermagem. Rio de Janeiro; 2007 [acesso em 2011 out 2]. Disponível em: http://www. portalcofen.gov.br/sitenovo/node/4158.

16. Acosta AM, Duro CLM, Lima MADS. Atividades do enfermeiro nos sistemas de triagem/classificação de risco nos serviços de urgência: revisão integrativa. Rev Gaúch Enferm [Internet]. 2012 [acesso em 2013 jun 26];33(4):181-90. Disponível em: http://seer.ufrgs.br/RevistaGauchadeEnfermagem/article/view/25239/23971.

17. Silva FD, Chernicharo IM, Ferreira MA. Humanização e desumanização: a dialética expressa no discurso de docentes de enfermagem sobre o cuidado. Esc Anna Nery Rev Enferm [Internet]. 2011 jun [acesso em 2011 out 1];15(2):306-13. Disponível em: http://www.eean.ufrj.br/revista_enf/vol15jun2/05ARTIGOS/11/v15n2a11.pdf.

18. Waldow VR, Borges RF. Cuidar e humanizar: relações e significados. Acta Paul Enferm. [Internet]. 2011 [acesso em 2011 out 2];24(3):414-8. Disponível em: http://www.scielo.br/pdf/ape/v24n3/17.pdf.

19. Dal Pai D, Lautert L. Sofrimento no trabalho de enfermagem: reflexos do "discurso vazio" no acolhimento com classificação de risco. Esc Anna Nery Rev Enferm [Internet]. 2011 set [acesso em 2011 out 2];15(3):524-30. Disponível em: http://www.scielo.br/pdf/ean/v15n3/a12v15n3.pdf.

20. Teixeira RR. Humanização e atenção primária à saúde. Ciênc Saúde Coletiva [Internet]. 2005 jul-set [acesso em 2011 out 2];10(3):585-97. Disponível em: http: / /www.scielosp.org/pdf/csc/v10n3/a16v10n3.pdf.

21. Schneider DG, Manschein AMM, Ausen MAB, Martins JJ, Albuquerque GL. Acolhimento ao paciente e família na unidade coronariana. Texto \& Contexto Enferm [Internet]. 2008 mar [acesso em 2011 maio 15];17(1):81-9. Disponível em: http://www.scielo.br/pdf/tce/v17n1/09.pdf.

22. Benevides R, Passos E. A humanização como dimensão pública das políticas de saúde. Ciênc Saúde Coletiva [Internet]. 2005 [acesso em 2011 out 2];10(3):561-71. Disponível em: http://www.scielosp.org/pdf/csc/v10n3/a14v10n3.pdf. 


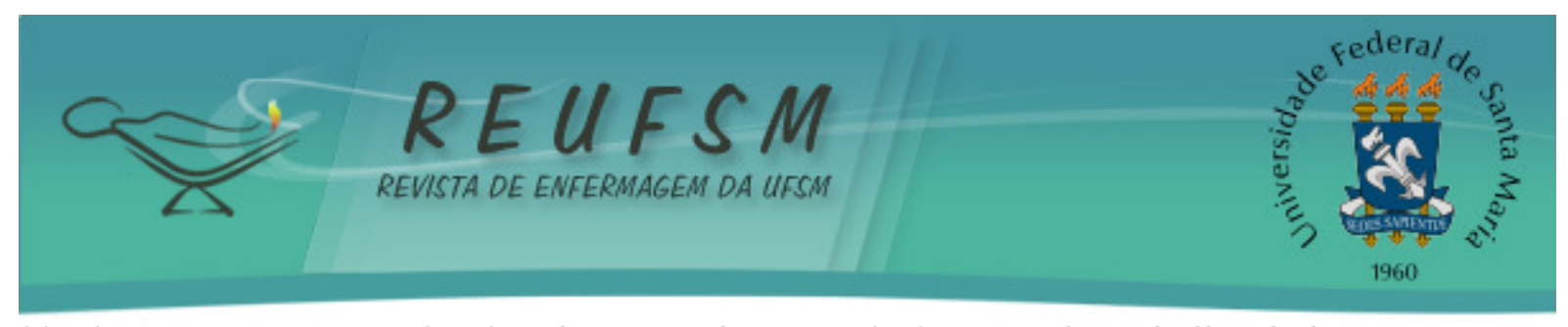

23. Garcia AV, Argenta CE, Sanchez KR, Thiago MLS. O grupo de trabalho de humanização e a humanização da assistência hospitalar: percepção de usuários, profissionais e gestores. Physis [Internet]. 2010 [acesso em 2011 out 2];20(3):811-34. Disponível em: http: //www.scielo.br/pdf/physis/v20n3/v20n3a07.pdf.

24. Dubeux LS, Freese E, Reis YAC. Avaliação dos serviços de urgência e emergência da rede hospitalar de referência no Nordeste brasileiro. Cad Saúde Pública [Internet]. 2010 ago [acesso em 2011 out 2];26(8):1508-18. Disponível em: http://www.scielo.br/pdf/csp/v26n8/05.pdf.

Data de recebimento: 20/03/2013

Data de aceite: $22 / 08 / 2013$

Contato com autor responsável: Alcides Viana de Lima Neto

E-mail: alcides.vln@gmail.com

Endereço: Rua Santo Antônio, 09, Casa, Centro, Coronel João Pessoa, Rio Grande do Norte, Brasil, CEP: 59930-000. 